\title{
Gender equality in STEM programs: a proposal to analyse the situation of a university about the gender gap
}

\author{
Alicia García-Holgado \\ GRIAL Research Group \\ University of Salamanca \\ Salamanca, Spain \\ aliciagh@usal.es \\ Jimena Pascual \\ Pontificia Universidad Católica de \\ Valparaíso \\ Valparaíso, Chile \\ jimena.pascual@pucv.cl \\ Lucy García-Ramos \\ Department of Systems Engineering \\ Universidad del Norte \\ Barranquilla, Colombia \\ lucyr@uninorte.edu.co
}

\author{
Juanjo Mena \\ GRIAL Research Group \\ University of Salamanca \\ Salamanca, Spain \\ juanjo_mena@usal.es \\ Mervi Heikkinen \\ Faculty of Education \\ University of Oulu \\ Oulu, Finland \\ mervi.heikkinen@oulu.fi \\ Rita Peñabaena-Niebles \\ Department of Industrial Engineering \\ Universidad del Norte \\ Barranquilla, Colombia \\ rpena@uninorte.edu.co
}

\author{
Francisco José García-Peñalvo \\ GRIAL Research Group \\ University of Salamanca \\ Salamanca, Spain \\ fgarcia@usal.es \\ Sari Harmoinen \\ Faculty of Education \\ University of Oulu \\ Oulu, Finland \\ sari.harmoinen@oulu.fi \\ Lucía Amores \\ GRIAL Research Group \\ University of Salamanca \\ Salamanca, Spain \\ luciaag10@usal.es
}

\begin{abstract}
According to the Global Gender Gap Report 2020, most of the countries have achieved gender parity in educational attainment. Furthermore, Latin America and Europe have more women than men enrolled in tertiary education. The problem arises when those numbers are analysed by degree studies. There is a gender gap in science, technology, engineering and mathematics (STEM), with a low number of women enrolled in those programs and even lower numbers of graduates. The universities have a key role to steer new conceptions and understanding of the females in STEM . The higher education institutions have to define measures and policies to reduce the gender gap in the careers of the future. This work aims to provide a proposal to analyse the gender equality gap in STEM as a first step to define gender equality action plans focused on processes of attraction, access and retention and guidance in STEM programs. The proposal was applied in ten Latin American universities from Chile, Colombia, Costa Rica, Ecuador and Mexico, and five European universities from Finland, Freland, Italy, Spain, United Kingdom.
\end{abstract}

Keywords-gender gap, self-analysis, STEM, framework, university.

\section{INTRODUCTION}

Nowadays, the greater participation of women in all sectors of society is evidenced. However, these advances have not occurred proportionally. In recent decades, various studies have highlighted the lack of scientific and technological vocations among pre-university students $[1,2]$. The European Union report published in 2007 highlighted the decline in young people's interest in science and mathematics, despite the initiatives developed to reduce it [3]. This interest is subsequently reflected in the desire to pursue a career in STEM (Science, Technology, Engineering and Mathematics).

This situation increases when variables such as gender, cultural and socio-economic context, or sexual orientation are introduced. In particular, women are one of the least represented groups in STEM areas [4]. The participation of women continues being low in STEM professions: $28 \%$ according to the UNESCO report [5]. A significant minority of women choose and access STEM programs at the tertiary level, which appear to be excluded from the options of studies in secondary school girls. Furthermore, many countries have not yet incorporated the culture of gender equality in their universities, nor the objective of allowing equal access to women in STEM in Higher education levels. Therefore, it is still a complex problem that requires actions from governments, the private sector and families, in addition to different levels of education (from childhood to higher education).

According to the World Economic Forum predictions [6], it would take around 100 years for women to be pairing their male counterparts' works, take over leadership roles at top institutions such as the World Bank and be prime ministers in the top ten countries for gender equality: Iceland, Norway, Finland, Sweden, Nicaragua, New Zealand, Ireland, Spain, Rwanda, and Germany.

Also, the World Economic Forum report about employment and prospective outlook states that around 26\% of jobs in the technology sector are carried out by women [7]. In the scientific field, according to the figures provided by UNESCO, only $28.8 \%$ of the work in the scientific sector is carried out by women [5]. Moreover, if this figure is analysed in terms of the different profiles within the scientific career, a clear increase in the gender gap can be observed. According to [8], the gender gap persists particularly in computer sciences, physics, maths and surgery with regard to senior teachers and researchers. As for leadership positions nowadays, female research leaders are not equal to male researcher leaders because inside and outside challenges at the workplace $[9,10]$.

These differences might be even wider in Latin America as [11] has reported in the representative context of Brazil. The situation is especially critical in the technology industry. Women only represent between $10 \%$ and $20 \%$ of the total labour market and are mainly concentrated in occupations that are not linked to technology production and senior management [7]. 
The Global Gender Gap Index seeks to measure the relative gaps between women and men across four key areas: health, education, economy and politics [12]. The last report published in December 2019 highlights that gender parity in education is almost complete, although there are some differences between regions and countries. In particular, the educational attainment subindex is composed of the female, male literacy rate, and the enrolment rates of female, male in primary, secondary and tertiary education. For example, although Colombia has more female than male enrolled in tertiary education, the percentage of male and female tertiary education graduates from STEM programs is not equal, with $13.76 \%$ females and $35.12 \%$ males, which means a score of 0.39 ( 1 means parity, lower than 1 means more male than female, and bigger than 1 means more female than male). This situation is repeated in other Latin American countries such as Chile, where the STEMS attainment score is 0.18 or Costa Rica, with a value of 0.30 . However, this situation is not only associated with Latin America but also in Western Europe the STEM programs are far from the gender parity, although it is the region where the gender gap is smaller. For example, in Finland, which is the third best-ranked country of the global gender gap index, only $12.39 \%$ of students in STEM programs are female, against $49.79 \%$ that are male (0.25 score). Also, other European countries, such as Ireland or Spain, have a similar situation with 0.38 and 0.33 scores respectively.

In this context, universities have a key role, not only inside the university but also as drivers of new behaviours and understandings within other sectors of society. The need for defining and implementing concrete actions to modernize the government, better managing higher education institutions to increase the number of women in STEM programs is highly regarded. In this sense, to define measures and policies, it is necessary to identify the situation of each individual university with regard to gender equality.

This work aims to present a proposal to analyse the state of a university about the gender gap through a set of instruments applied and further developed in the frame of the W-STEM project, a European research project funded by the Erasmus + Programme, which involves countries from Latin America and Europe.

The rest of the document is organized as follows. Section 2 describes the details about the project "Building the future of Latin America: engaging women into STEM" (W-STEM). Section 3 presents the methodology to measure the situation of the universities with regard to gender equality. Section 4 describes the application of the methodology within the project. Finally, the last section summarizes the main conclusions derived from this work.

\section{W-STEM PROJECT}

W-STEM is a European project that is coordinated by the GRIAL Research Group [13] at the University of Salamanca (Spain). It also counts on the participation of fourteen other partners from different countries in Europe and Latin America (Table I), plus the presence of UNESCO, as an associate partner. Its main objective is to improve the strategies and mechanisms of attraction, access and guidance of women in STEM higher education programs in Latin America.
Although there are different projects and studies focused on analysing and systematise the obtention of quality data that allows the generation of comparable statistics and indicators which show the actual situation of women, as well as their progress, there is a lack of information in Latin America. The UNESCO SAGA project (STEM and Gender Advancement) [14], the UNESCO Institute for Statistics [5] or the Global Gender Gap Report made since 2006 [12, 15] provide global indicators that draw a picture of the situation. However, there is no particular information about the situation of each institution, and the measures and policies that they have to implement according to the socio-cultural and economic factors of their contexts. Moreover, there is no full process and instruments that each university could apply to collect the required information to identify where it is necessary to make changes.

TABLE I. W-STEM PROJECT DETAILS

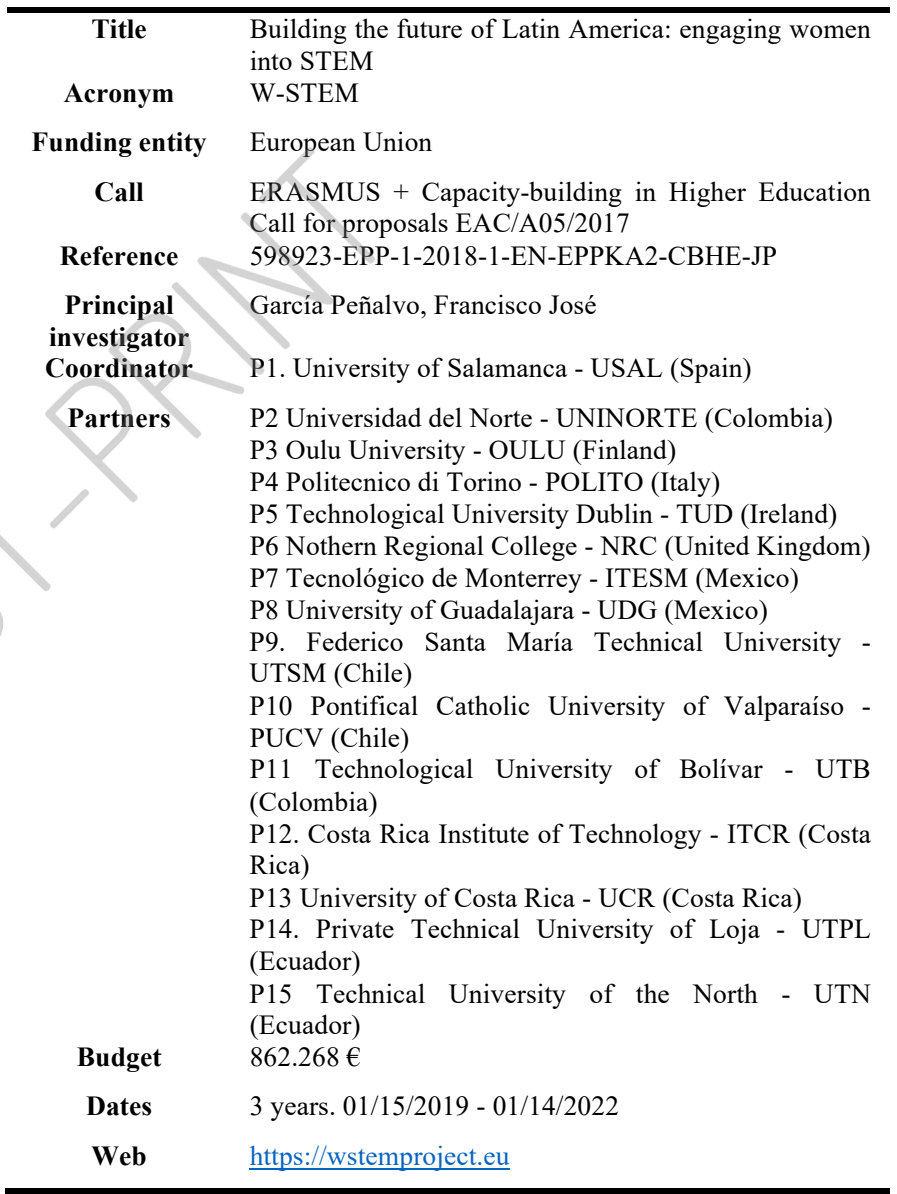

For this reason, the first objective of the W-STEM project is to measure the gender equality in enrolment and retention rates in STEM programs - Natural sciences and mathematics; Information and communication technology and Engineering, manufacturing and construction- at undergraduate levels $[16,17]$.

The first year of the project was dedicated to analysing the situation of the universities involved in the project in order to have enough information to prepare the gender equality action plan that will be carried out during the next two years of the project. Each Latin American institution defined the action plan at the end of the first year in a workshop conducted in University of the North 
(Barranquilla, Colombia) as part of the W-STEM International Leadership Summit (25-29 November 2019). The action plan covers three axes. First, the attraction processes to conduct activities that have an impact on the number of females who apply for STEM programs. Second, the access processes, in order to ensure a higher conversion rate of applicants to enrolled students. Finally, the retention and guidance processes in order to reduce the dropout of students in STEM programs [18-20], with a particular focus on women.

\section{Methodology}

To know what the situation of women in STEM programs in Latin America and Europe is at present, as well as to verify if there is any significant gender gap manifested, a survey research method [21] was followed to collect the required information. Noteworthy that health science is not covered by W-STEM project, only the following fields of ISCED 2013 classification: natural sciences and mathematics; information and communication technology; and engineering, manufacturing and construction.

The process to get an overview of the gender equality in STEM programs in a university follows three phases (Fig. 1), each one with an instrument associated with collecting the required information, and a dataset that serves as input for the definition of the gender equality action plan in STEM programs. The first phase is focused on a self- assessment based on collecting quantitative indicators from the different services and units that conform to the institution. The second phase collects the different processes implemented in the university for the attraction of students, the access and enrolment processes, and the activities, protocols, for retention and guidance of students. Finally, the third phase aims to identify best practices conducted in the university in order to serve as a seed to define other practices and establish a connection between them.

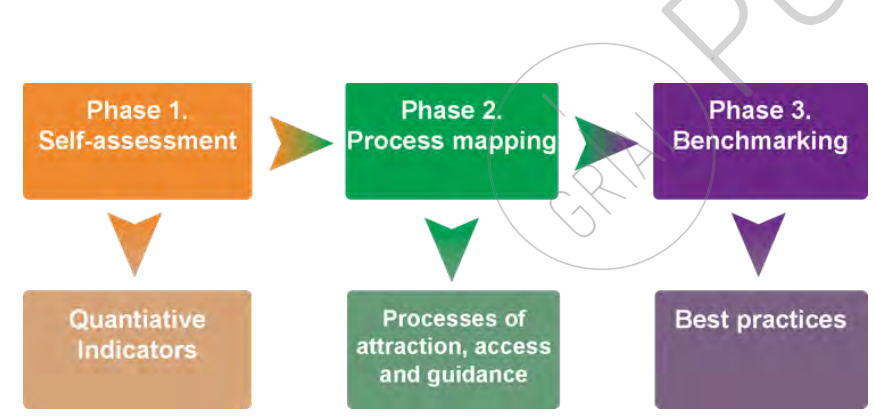

Fig. 1. Phases and results of the self-analyse process of gender equality in STEM programs at the university.

\section{A. Self-assessment}

First, the self-assessment phase is conducted. The main objective of this self-assessment is to analyse the current situation of the university concerning gender equality in STEM programs. For this, the different processes on attraction, access, guidance and retention have been taken into account.

A survey was defined to analyse the current state of each university concerning the attraction, access, guidance, retention, among other processes, only on the quantitative side. The survey design is key for the rest of the process, as this will determine the scope and starting point of the institution considering gender equality in the three main processes to be improved.

The survey is based on the UNESCO SAGA Toolkit [22], which purpose is to collect information on gender equality policies in Science, Technology and Innovation. Questions were selected from the SAGA Indicator Matrix [22] (Table 8, p. 57-59) that is pertinent to W-STEM project goals having focus to higher education (indicators from 4-26) and just modified one, the indicator 9 "Total and share of women graduated from university programs by field of study and by educational level," leaving only the indicator according to the field study. Besides, two indicators have been added, indicator 46 concerning the guidance of women enrolled and graduated in STEM programs, based on SAGA indicator 9; and indicator 47 to measure female dropout in STEM programs [17]. The indicators cover ten core themes: university background information (total number of students and staff: males/females); STEM Programmes according to ISCED 2013 classification - broad field; students; attraction; access; enrolment; discrimination; sexual harassment; guidance; dropouts.

The survey is implemented in a spreadsheet due to length and multiple variables contained in the instrument. It is available in [23]. The survey is organised in 26 sections, 10 of which are marked to indicate that they are most relevant to examine attraction, access and guidance of women in STEM fields at the institutional level (Fig. 2). The university can provide the information according to the level of availability, either aggregate data (university total for STEM programs) or by fields of study for STEM programs (ISCED-F 2013 variants).

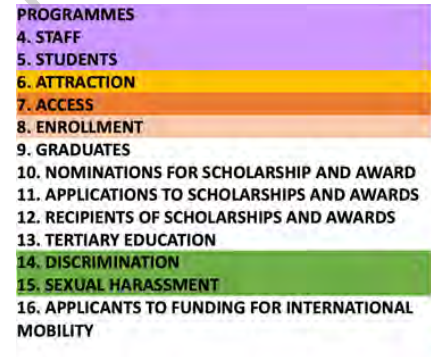

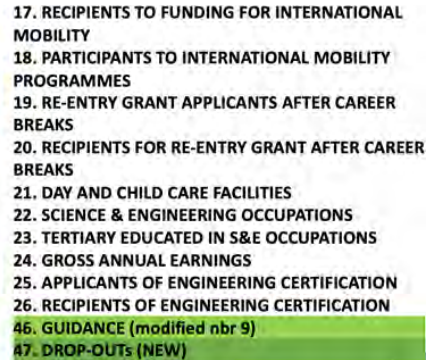

Fig. 2. Main sections of the self-assessment survey.

The self-assessment is focused on undergraduate education level only (bachelor's degree or equivalent) and one academic year, although it is possible to use it for a master's degree or doctorate. Also, it is possible covering more academic years, although it is recommended to analyse only the last academic year due to the difficult to collect the indicators due to a challenge to feed the indicators with sufficient data.

\section{B. Process mapping}

Secondly, a mapping of the internal process of attraction, access, guidance and retention of students in STEM programs is carried out, with a particular focus on processes associated to female students or those that not take into account gender equality.

This mapping is useful for the institution to determine all the steps involved in the mentioned processes for women in STEM programs, the main stakeholders that take part in the 
process, and the requirements to introduce changes and improvements. The data obtained from the university throughout the mapping process will complement the information collected through the indicators of the selfassessment matrix.

A spreadsheet template is available in [24] to support this phase. The template has four datasheets, one per each macro categories (attraction, access, guidance and retention). Each sheet provides a set of columns to organize the input information. In particular, each category is divided into subcategories. For example, the attraction category could be divided into the definition of the promotion plan, application the promotion plan, evaluation of the promotion plan, social networks, etc. The subcategory depend on the institution.

Moreover, each subcategory is divided into activities and the following information is provided: the name of the activity, a short description of the activity and the impact in the target groups. Finally, the departments, services or units in charge of each subcategory and/or activity should be provided. This information is useful when the gender quality action plan is defined in order to involve those services or units that can implement the measures and policies.

\section{Benchmarking}

Finally, the third phase is focused on the compilation of good practices that are developed in each institution. The institution has to collect examples of good practices that might be interesting and of novelty from an institutional point of view. This could be related to any of the three processes (attraction, access and orientation); it may even have an impact on more than one process at a time.

After collecting the good practices inside the institution, it is recommended to conduct a benchmarking round with other institutions as a way to share good practices and learn from others. The methodology proposed to conduct the benchmarking round is based on the Columbus Association methodology [25].

A questionnaire based in the Columbus methodology is completed for each good practice identified. The questionnaire is provided with some instructions to understand better the dynamic, the way the questionnaire will be used, and therefore, the nature of the answers required.

The benchmarking round is looking for those cases that have the biggest potential for collaborative learning, not only the successful ones. Projects at any stage (planning/execution/evaluation) as well as programs and services in creation, development or closing phases are equally interesting, as long as they offer an experience from which people can learn. The good practices are organized in three axes:

- The attraction of women to STEM programs.

- Recruitment and access of women to STEM programs.

- Retention and talent empowerment during STEM training: science and technology teaching.

The questionnaire is divided into four blocks. First, a set of questions to describe the practices and the relation to the benchmarking axes. A second block related to institutional strategies and policies. The third block has questions about the implementation and sustainability of the good practice. The fourth block bring together questions related to future improvements focused on women in STEM programs. The questionnaire is available as a PDF form in [26].

\section{W-STEM SELF-ASSESSMENT}

The self-analysis process to get an overview of the gender equality in a university was applied within the $\mathrm{W}$ STEM project to have enough information to prepare the gender equality action plan that will be carried out during the next two years of the project. The action plans will be applied only in the Latin American institutions due to the profile of the European institutions is to transfer knowledge and support Latin American institutions in the improvement of women in STEM. Despite this, the European institutions decided to apply also the self-analysis as a way to test the process and get relevant information also to improve their processes.

Each of the universities involved in the W-STEM project has collaborated in providing current data from their institutions (updated to the last course 2018-2019). In this way, each institution has an initial idea of where to start the definition of their action plans. The information has been collected through different researchers and stakeholders in the participants' institutions following the three phases previously described: (1) self-assessment, (2) process mapping and (3) benchmarking.

First, the self-assessment survey was handed out in each of the participating universities in the project. The data that were collected corresponds to the 2018-2019 academic year. An overview of the data collected in the first phase is presented in this paper. Although there are 26 indicators, only those associated with the ten core themes were used in this analysis due to the other indicators are not provided by all the institutions:

- Female staff in STEM programs.

- Female students enrolled in STEM programs.

- Female applicants in STEM programs.

- Female applicants accepted in STEM programs.

- Female applicants enrolled in STEM programs.

- Female students graduated in STEM programs.

The data was collected by each institution. The analysis assumes that the data provided by the institutions have been duly reviewed. Table II shows the percentage of female students in the processes associated with access and retention. The aim of the analysis is not to compare the institutions, but to obtain an overview of the situation of each institution and to identify the available sources of data as well as possible gaps in institutional statistics that could be further improved as W-STEM project actions. Among their initiatives, they have embedded STEM subjects into our curriculum focussing on the practical and industrial application of the subjects to help promote employment opportunities. 
TABLE II. PERCENTAGE OF FEMALES IN STEM PROGRAMS. 2018-2019 ACADEMIC YEAR.

\begin{tabular}{|c|c|c|c|c|c|c|c|c|c|c|c|c|c|c|c|}
\hline & \multicolumn{5}{|c|}{ Europe (EU) } & \multicolumn{10}{|c|}{ Latin America (LA) } \\
\hline & NRC & OULU & $\begin{array}{l}\text { POLIT } \\
\text { O }\end{array}$ & TUD & USAL & ITCR & PUCV & ITESM & UCR & UDG & $\begin{array}{l}\text { UNINO } \\
\text { RTE }\end{array}$ & UTN & UTB & USM & UTPL \\
\hline Female staff & 43,75 & 34,18 & 35,31 & 32,01 & 33,41 & 21,52 & 37,53 & 44,75 & 27,67 & - & 26,17 & 24,92 & 21,43 & 19,97 & 45,45 \\
\hline F. applicants & 56,50 & 38,69 & 30,85 & - & 42,54 & 42,80 & 29,76 & 45,39 & 39,92 & - & 35,47 & 31,19 & 34,09 & 30,51 & 42,86 \\
\hline $\begin{array}{l}\text { F. applicants } \\
\text { accepted }\end{array}$ & 48,90 & 36,78 & 31,53 & - & 46,03 & 34,83 & 28,70 & 39,03 & 41,76 & 31,70 & 35,15 & 33,55 & 30,96 & 30,41 & 6,00 \\
\hline $\begin{array}{l}\text { F. applicants } \\
\text { enrolled }\end{array}$ & 48,90 & 35,93 & 29,89 & 25,55 & 41,05 & 30,97 & 27,97 & 36,70 & 43,44 & - & 31,94 & 34,21 & 30,96 & 29,55 & 6,00 \\
\hline $\begin{array}{l}\text { F. students } \\
\text { graduated }\end{array}$ & 64,03 & 42,86 & 30,31 & 23,74 & 35,27 & 37,24 & 36,32 & 34,56 & 37,17 & 28,56 & 34,56 & 32,47 & 30,94 & 26,23 & 30,00 \\
\hline
\end{tabular}

\% Female aplicants, accepted, enrolled students. STEM Programs

$\|$ Aplicants $\square$ Accepted $\square$ Enrolled

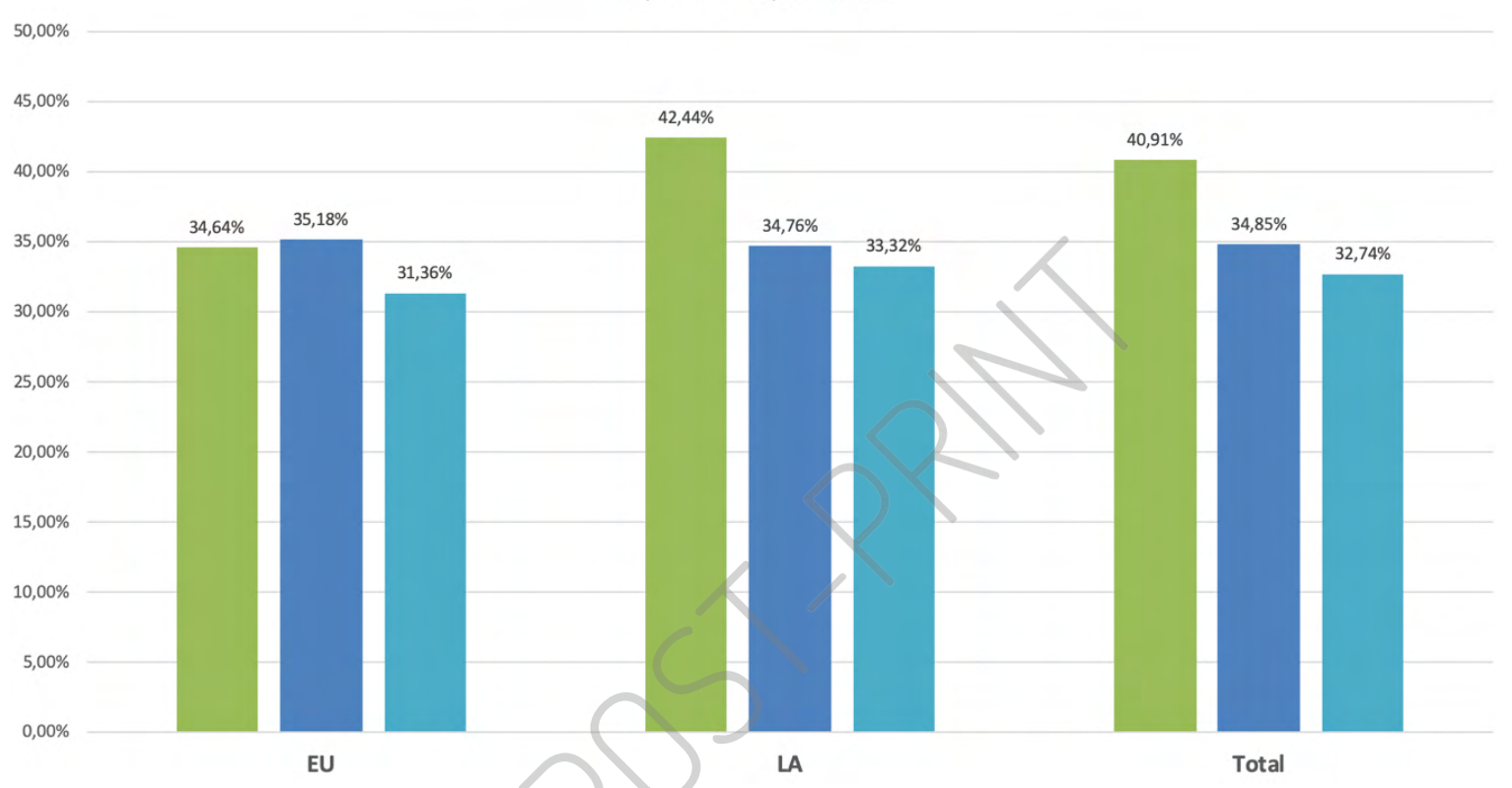

Fig. 3. Summary of the average of female students in the access proceses (applicants, accepted, and applicants enrolled) in the 2018-2019 academic year.

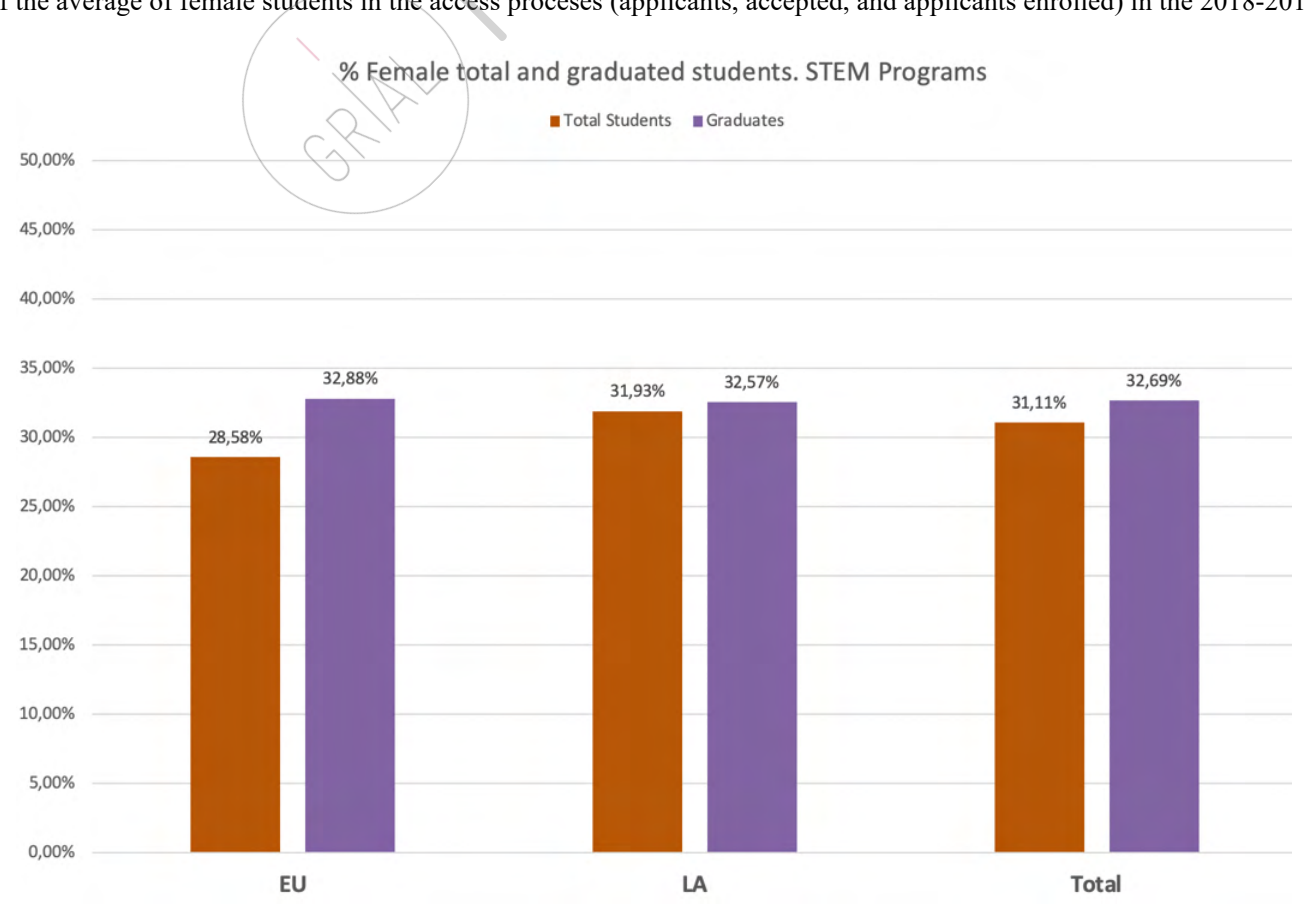

Fig. 4. Summary of the average of female students in STEM programs and female studdents graduated during the 2018-2019 academic year. 
According to the percentages showed in Table II, the NRC (North Ireland, United Kingdom) is the only institution that shows equal numbers on female and male students. They have more applications from female than male $(56.50 \%)$, and about $50 \%$ were accepted and formalised their enrolment. Besides, the number of female students that finish their STEM studies is bigger than males in 2018-2019. This institution has large expertise and success in attracting females to STEM courses.

Regarding the female staff, that also can influence in the guidance and retention of female students in STEM programs, USM (Chile), ITCR (Costa Rica) and UTB (Colombia) have the lowest frequency counts for female staff in STEM programs, that is to say, most of the teachers and professionals in those careers.

Also, it is important to analyse the conversation rate of female applicants. Most of the institutions show a decrease between female applicants and female applicants accepted. Also, there is a further decrease between the females accepted and those finally complete the enrolment process. Particularly worrying is the loss of women in the UTPL, where the percentage of women applying is low, but far from the percentage of women applying for STEM programs.

Those differences are shown in Fig. 3. It provides a comparative overview between European institutions and Latin American institutions but also allows to identify the gap between the applications and the enrolments of female students in STEM programs, which is particularly worrying in Latin America, where there are near to $43 \%$ of female applicants in STEM programs, but women only represent $33 \%$ of the final enrolments.

Regarding Fig. 4, shows the total percentages of female students enrolled in STEM programs (not in the first year) in the European and Latin American institutions during the 2018-2019 academic year, and the total number of female students graduated in those programs at the end of the 2018 2019 academic year.

\section{DisCUSSION AND CONCLUSTON}

The gender gap in STEM is a reality that affects all countries to a greater or lesser extent. Even though globally more women than men are enrolled in tertiary education, these figures are not the same if each field is analysed separately, and there is a wide gender gap in STEM programmes.

The university must be the promoter of strategies and mechanisms to reduce this gender gap. To this end, higher education institutions must implement gender equality action plans based on their gender equality situation. This work presents a process composed of a set of phases and instruments that allows the institution to make a self-analysis as a seed to detect points of improvement in the processes of attraction, access, guidance and retention in the STEM programs.

Moreover, although the self-analysis serves as an input of the gender equality action plans defined by each university involved in the W-STEM project, also serves as a tool to compare the impact of the action plans. The same process will be applied at the end of the project in order to compare the indicators and the processes before and after applying the action plan. It is important taken into account that three years is not enough time to measure the change in some indicators. Leaving aside the time frame for financing the project, an institution should define a longer period of time to measure the real impact of the changes implemented.

The main conclusion from the early results of the selfassessment in the W-STEM project shows that still work to do since most of the universities show percentages around $30 \%$ in the leading indicators analysed.

These data dismount the unsupported belief that there are gender innate differences in sciences [27]. Although there should be constant efforts made to recruit and retain women in those careers in order to keep growing the percentage of women in STEM in both regions, Latin America and Europe.

According to [8] the "STEM gender gap will not close without further reforms in education, mentoring, and academic publishing" (p.1). The Triple helix approach has been found to be useful. This approach is an integrated effort made by universities, industry and government to develop national policies towards reducing the gender gap. For example, in Costa Rica [28] this approach shows good results.

Industry and government have to implement measures such as to afford recognition of the extra social demands for women [9]; guarantee more resources at the workplace [29], better parental leave conditions [30] and better circumstances for hiring. Those measures will complement the strategies and mechanism implemented by the universities.

Regarding the self-analysis process, a number of important limitations need to be considered. First, it is important to highlight the difficulties to access the information. The self-assessment and the mapping process require the collaboration of different services and units within each higher education institution and country. None of the universities involved in the W-STEM project has a unique service, e.g. gender equality office collecting and managing statistical information, that has all the information about the attraction, access and guidance processes. On the other hand, in the Latin American context, the institutions had problems to understand ISCED 2013 classification, although it is an international standard.

Finally, it would be interesting to apply the self-analysis process in other higher education institutions, not only in Latin America and Europe but also in other regions as a way to compare the differences among regions.

\section{ACKNOWLEDGMENT}

This work has been possible with the support of the Erasmus + Programme of the European Union in its Key Action 2 "Capacity-building in Higher Education". Project W-STEM "Building the future of Latin America: engaging women into STEM" (Reference number 598923-EPP-12018-1-ES-EPPKA2-CBHE-JP). The content of this publication does not reflect the official opinion of the European Union. Responsibility for the information and views expressed in the publication lies entirely with the authors.

\section{REFERENCES}

[1] B. Convert and F. Gugenheim, "Scientific Vocations in Crisis in France: Explanatory Social Developments and Mechanisms," 
European Journal of Education, vol. 40, no. 4, pp. 417-431, 2005, doi: $10.1111 / \mathrm{j} .1465-3435.2005 .00237 . x$.

[2] B. Convert, "Europe and the Crisis in Scientific Vocations," European Journal of Education, vol. 40, no. 4, pp. 361-366, 2005, doi: 10.1111/j.1465-3435.2005.00233.x.

[3] M. Rocard, P. Csermely, D. Jorde, D. Lenzen, H. Walwerg-Heriksson, and V. Hemmo, EUR22845 - Science Education NOW: A renewed Pedagogy for the Future of Europe. Luxembourg: Office for Official Publications of the European Communities, 2007.

[4] A. García-Holgado, C. S. González, and A. Peixoto, "Bridging the diversity gap in STEM," in Proceedings of the 7th International Conference on Technological Ecosystems for Enhancing Multiculturality (TEEM 2019) (León, Spain, October 16-18, 2019), M. Á. Conde-González, F. J. Rodríguez Sedano, C. Fernández Llamas, and F. J. García-Peñalvo Eds., (ACM International Conference Proceeding Series (ICPS). New York, NY, USA: ACM, 2019, pp. 193-195.

[5] UNESCO Institute for Statistics, "Women in Science," UNESCO Institute for Statistics, FS/2018/SCI/51, 2018. Accessed: 10/08/2019. [Online].

Available: http://uis.unesco.org/sites/default/files/documents/fs51-women-inscience-2018-en.pdf

[6] World Economic Forum, K. Schwab, Ed. The Global Competiteviness Report 2019. Geneva, Switzerland: World Economic Forum, 2019.

[7] World Economic Forum, "The Industry Gender Gap: Women and Work in the Fourth Industrial Revolution," World Economic Forum, Geneva, Switzerland, 2016. [Online]. Available: http://bit.ly/2HoKv0Z

[8] L. Holman, D. Stuart-Fox, and C. E. Hauser, "The gender gap in science: How long until women are equally represented?," PLoS Biol, vol. 16, no. 4, p. e2004956, 2018, doi: 10.1371/journal.pbio.2004956.

[9] E. Nicholson, "Accounting for career breaks," Science, vol. 348, no. 6236, 2015, doi: 10.1126/science.348.6236.830.

[10] J. M. Sheltzer and J. C. Smith, "Elite male faculty in the life sciences employ fewer women," Proceedings of the National Academy of Sciences, vol. 111, no. 28, pp. 10107-10112, 2014, doi: 10.1073/pnas.1403334111.

[11] B. Stefanello Lima, M. Lopes Maria, and M. Conceição da Costa, "Programa mulher e ciencia: breve análise sobre a política de equidade de género nas ciéncias, no Brasil," in Memoria del XI Congreso Iberoamericano de Ciencia, Tecnología y Género (San José, Costa Rica), 2016.

[12] World Economic Forum, Insight Report. The Global Gender Gap Report 2020. Geneva, Switzerland: World Economic Forum, 2019.

[13] F. J. García-Peñalvo, M. J. Rodríguez-Conde, R. Therón, A. GarcíaHolgado, F. Martínez-Abad, and A. Benite-Santes, "Grupo GRIAL," IE Comunicaciones. Revista Iberoamericana de Informática Educativa, vol. 30, no. 33-48, 2019.

[14] UNESCO, "STEM and Gender Advancement (SAGA): improved measurement of gender equality in science, technology, engineering and mathematics," 2016. [Online]. Available: http://bit./y/2m8oOdS

[15] World Economic Forum, Insight Report. The Global Gender Gap Report 2018. Geneva, Switzerland: World Economic Forum, 2018.

[16] A. García-Holgado, A. Camacho Díaz, and F. J. García-Peñalvo, "La brecha de género en el sector STEM en América Latina: una propuesta europea," in Aprendizaje, Innovación y Cooperación como impulsores del cambio metodológico. Actas del V Congreso Internacional sobre Aprendizaje, Innovación y Competitividad. CINAIC 2019 (9-11 de Octubre de 2019, Zaragoza, España), M. L. Sein-Echaluce Lacleta, Á. Fidalgo Blanco, and F. J. García-Peñalvo Eds. Zaragoza, Spain: Servicio de Publicaciones Universidad de Zaragoza, 2019, pp. 704-709.

[17] A. García-Holgado, A. Camacho Díaz, and F. J. García-Peñalvo, "Engaging women into STEM in Latin America: W-STEM project," in Proceedings of the 7th International Conference on Technological Ecosystems for Enhancing Multiculturality (TEEM 2019) (León, Spain, October 16-18, 2019), M. Á. Conde-González, F. J. Rodríguez Sedano, C. Fernández Llamas, and F. J. García-Peñalvo Eds., (ACM International Conference Proceeding Series (ICPS). New York, NY, USA: ACM, 2019, pp. 232-239.

[18] L. Paura and I. Arhipova, "Cause Analysis of Students' Dropout Rate in Higher Education Study Program," Procedia - Social and Behavioral Sciences, vol. 109, pp. 1282-1286, 2014/01/08/ 2014, doi: https://doi.org/10.1016/j.sbspro.2013.12.625.

[19] L. Salas-Morera, A. Cejas Molina, J. L. Olivares Olmedilla, L. García-Hernández, and J. M. Palomo-Romero, "Factors Affecting Engineering Students Dropout: A Case Study," International Journal of Engineering Education, vol. 35, no. 1, pp. 156-167, 2019.

[20] I. Isphording and P. Qendrai, "Gender Differences in Student Dropout in STEM," in "IZA Research Reports," IZA Institute of Labor Economics, Bonn, Germany, 87, 2019.

[21] J. Janes, "Survey research design," Library Hi Tech, vol. 19, no. 4, pp. 419-421, 2001, doi: 10.1108/EUM0000000006543.

[22] UNESCO, Measuring gender equality in science and engineering: the SAGA toolkit. $\$ A G A$ Working Paper 2. Paris, France: UNESCO, 2017.

[23] W-STEM Consortium, "W-STEM Self-assessment Matrix," 2019. [Online]. Available: https://doi.org/10.5281/zenodo.3594822

[24] W-STEM Consortium, "W-STEM Process Mapping Template," 2019. [Online] Available: https://doi.org/10.5281/zenodo.3594845

[25] Columbus Association. "U-Benchmarking Club." https://www.columbus-web.org/es/que-hacemos/desarrollo-decompetencias.html (accessed 29 December, 2019).

[26] W-STEM Consortium, "W-STEM Benchmarking Questionnaire $\begin{array}{llll}\text { Form," } & 2019 . & \text { [Online]. } & \text { Available: }\end{array}$ https://doi.org/10.5281/zenodo.3594858

[27] B. A. Barres, "Does gender matter?," Nature, vol. 442, pp. 133-136, 2006.

[28] M. F. Bartels, "Attaching the gender gap in Technology: A triple Helix Case Study," in Proceedings of the International Conference on Gender Research ICGR 2018, Porto, Portugal, 12-13 April 2018, A. Azevedo and A. Mesquita Eds. Reading, UK: Academic Conferences and Publishing International Limited, 2018.

[29] J. Duch et al., "The possible role of resource requirements and academic career-choice risk on gender differences in publication rate and impact," PLoS ONE, vol. 7, no. 12, p. e51332, 2012, doi: 10.1371/journal.pone.0051332.

[30] A. K. Shaw and D. E. Stanton, "Leaks in the pipeline: separating demographic inertia from ongoing gender differences in academia," Proceedings of the Royal Society B: Biological Sciences, vol. 279, no. 1743, pp. 3736-3741, 2012, doi: 10.1098/rspb.2012.0822. 